\title{
ENTENDER LA CIUDAD A TRAVÉS DEL DESARROLLO DEL GINE EN BADAJOZ A INICIOS DEL S.XK
}

\section{UNDERSTANDING THE GITY THROUGH THE DEVELOPMENT OF GINEMA IN BADAJOZ AT THE BEGINNING OF THE 20TH GENTURY}

\author{
ANA GONZÁLEZ DELGADO
}

JAVIER TRABADELA ROBLES

Profesores del Departamento de Información y Comunicación

de la Universidad de Extremadura (España)

Facultad de Ciencias de la Documentación y la Comunicación.

Universidad de Extremadura.

Plazuela Ibn Marwan,s/n. Badajoz (España) C.P. 06001

Tfno.: + 34924286400

Email: agondel@unex.es, jtrarob@unex.es

PALABRAS CLAVES

Cine, ciudad, análisis, social, urbano, modernización
KEY WORDS

Cinema, city, analysis, social, urban, modernization 


\title{
Resumen
}

El artículo que aquí se muestra trata de establecer un nexo de unión entre el florecimiento de un fenómeno cultural como fue el cinematógrafo a principios del siglo XX en la ciudad de Badajoz y su urbanismo. Una mediana localidad provinciana fronteriza que consiguió atraer a un público ávido de diversión en una época poco proclive para el ocio por los problemas sociales y económicos de la España de las primeras décadas del s. XX. El cine, su desarrollo, expansión y posterior implantación nos proporcionan herramientas de análisis crítico para observar y entender las ciudades que poblamos. Y nos permite sacar interesantes conclusiones sobre la relación estrecha entre el avance urbanístico y el asentamiento de nuevos centros culturales. Así es como también las pequeñas muestras de cine de asuntos locales que dejaron los fotógrafos aficionados nos suministran un perfil social de esta ciudad de provincias y muestran a través de sus rudimentarios rodajes el urbanismo emergente y sus costumbres. Es de esta manera como el cine también es protagonista de la gran aventura de la modernización urbana, en unos momentos de recuperación económica que irán paralela a la apertura de nuevas salas.

\begin{abstract}
This article establishes a link between the flourishing of a cultural phenomenon such as the cinematograph at the beginning of the 20th century in the city of Badajoz and its urbanism. A medium-sized provincial border town that managed to attract an avid crowd of fun at a time unlikely for leisure by the social and economic problems of Spain in the first decades of 20th century. The cinema, its development, expansion and subsequent implantation provide us with critical analysis tools to observe and understand the cities we live in. And it allows us to draw interesting conclusions about the close relationship between urban development and the establishment of new cultural centers. This is also how the small film shows of local affairs left by amateur photographers provide us with a social profile of this provincial city and show through its rudimentary filming the emerging urbanism and its customs. It is in this way that the cinema is also the protagonist of the great adventure of urban modernization, in moments of economic recovery that will parallel the opening of new movies theaters.
\end{abstract}




\section{Introducción}

En la ciudad de Badajoz se asentaron las primeras barracas de cine que visitaban las ciudades extremeñas en fiestas y ferias a principios del siglo XX. Los lugares elegidos siempre guardaban estrecha relación con otras salas, principalmente los más importantes coliseos, pero su ubicación también estaba ligado a los puntos neurálgicos de la ciudad. Así fue como después las salas de exhibición estarían ubicadas en el interior del recinto amurallado donde esta localidad todavía no había conseguido romper esas barreras para su expansión. En las primeras décadas del siglo XX existe un paralelismo claro entre urbanismo y cine con una conexión marcada por el principal coliseo de la ciudad, el teatro López de Ayala, un ejemplo claro y que ha perdurado en el tiempo de la arquitectura del ocio (Lozano, 1998). Él cine, de esta manera, se va asentando en recintos ya utilizados para acontecimientos culturales, pero también aprovechará espacios urbanos de esparcimiento de los ciudadanos y monumentos que recordaban las gloriosas hazañas bélicas de Badajoz en los baluartes defensivos de los siglos XVI y XVII, sin dejar de lado los puntos de actividad comercial, nunca muy alejados unos de otros.

El contexto social, económico y político de la ciudad transfronteriza de Badajoz a principios del siglo XX marcó especialmente el desarrollo de uno de los acontecimientos culturales más notables a finales del siglo XIX y principios del XX, como es la implantación del cinematógrafo. A pesar de que su situación económica no auguraba una expansión rápida, la fascinación por un invento que tantas novedades aportaba al ocio extremeño puede ser una de las causas que expliquen por qué se convirtió en un fenómeno de masas en poco tiempo. También fue un factor determinante el hecho de que el cine era un espectáculo bastante asequible, mucho más que las representaciones teatrales, las zarzuelas o las varietés tan de moda en la época. Su difusión fue paralela a ciudades cercanas como Mérida y Cáceres, pero la capital pacense se convirtió en los años veinte en el centro de las grandes distribuidoras, atraídas por la aceptación de sus habitantes, el emergente público portugués y las mejoras económicas que se dieron de forma peculiar en Badajoz. El ferrocarril, los empresarios ambulantes primero y las grandes empresas de exhibición después hicieron que en tan sólo diez años se pasara de esporádicas sesiones a contar con más de cinco salas abiertas y cerca de 400 exhibiciones al año.

En un contexto de recuperación económica en los años veinte y con el impulso de modernización de la sociedad española de principios de siglo, se encuentran puntos de conexión entre una emergente capital de provincia y el florecimiento de las salas de exhibición cinematográficas no solo en Badajoz, en toda la provincia se vislumbra un fenómeno que irá asentándose en los años posteriores en ciudades como Mérida, Montijo, Azuaga, Don Benito, Villanueva de la Serena, entre otras (Cardoso, 2015). Los rodajes de asuntos locales mostrarán a los pacenses las imágenes reales de una ciudad mostrando emblemáticos edificios que hasta ese momento solo podían ser conocidos al pasear por Badajoz. El cine se convierte en una forma de acercar la urbe a quienes no conocían de cerca paisajes urbanos. 


\section{Objetivos}

En este trabajo se trata de demostrar cómo la situación estratégica de las salas de exhibición estuvo señalada por el urbanismo y los usos y costumbres de los ciudadanos de Badajoz y por ello se marca los siguientes objetivos:

- Analizar la ubicación de las salas de exhibición.

- Estudiar el papel que tuvo en este asentamiento el principal coliseo de la ciudad, el teatro López de Ayala.

- Identificar las costumbres de ocio marcadas por la tradición secular de una ciudad provinciana como Badajoz.

\section{Metodología}

Este análisis parte de un estudio más extenso sobre La exhibición cinematográfica en Badajoz (19141929) (González, 2016), que se presentó como tesis doctoral en la Universidad Complutense de Madrid. Si bien solo formaba parte de la contextualización cultural para ubicar el fenómeno cinematográfico sirve como hilo conductor para ahondar en las relaciones entre cine y urbanismo. Además de recurrir a dicha investigación se ha procedido a la lectura de otros trabajos realizados sobre este mismo fenómeno tanto en España (Barrientos-Bueno, 2017) como en Sudamérica (Rodríguez, 2017), así como estudios históricos sobre el Urbanismo en Extremadura (Lozano, 1998) con el que se encuentran algunos puntos en común y similitudes. Se han establecido sobre el plano de la ciudad las áreas en las que se ubicaban espacios y locales de distinta naturaleza cultural y se ha establecido un paralelismo con la disposición de dichos edificios y usos con la situación actual a través de fotografías y planos actuales de la ciudad.

\section{El contexto urbano, social y cultural de la ciudad de Badajoz a principios del siglo $\mathrm{XX}$}

La influencia del urbanismo en el desarrollo y expansión del cine no parece un asunto insustancial si tenemos en cuenta como su expansión y progreso se realiza en función de las infraestructuras más básicas. Es cierto que no se puede abordar este tema sin conocer las características sociales y económicas más elementales de la ciudad de Badajoz, situada en el suroeste español. Localidad transfronteriza con Portugal, que oscilaba entre los 25.000 habitantes (Bohoyo, 1984) en 1914 hasta los 37.576 personas, registrados tres años después en 1917, según el Boletín de Estadísticas Municipales de Badajoz. Aunque estas diferencias de datos podían obedecer a la llegada de diversos regimientos militares cuyos efectivos variaban de forma constante en la capital pacense.

Badajoz vivía inmersa en un ambiente en que se mezclaban las explotaciones rurales, los pequeños comercios y un gran número de militares. Apenas si existían industrias. Mención aparte merece nombrar 
la dependencia de un pasado castrense donde pervivía una sociedad militar, actividad histórica heredada desde siglos anteriores cuando las guerras con Portugal obligaron a crear una infraestructura defensiva que perduraba a principios del siglo XX.

Badajoz era la sede de la Capitanía General del distrito militar de Extremadura y en ella estaban asentados los regimientos de Infantería Castilla 16 y Gravelinas $n^{\circ} 41$; el de Caballería de Villarrobledo; el parque de Ingenieros; una pequeña Unidad de Artillería e unidades de Intendencia; el Hospital Militar y a partir de 1925 el cuartel de Menacho al que se traslada el de Gravelinas. Todas estas instalaciones albergaban a más de 6.000 militares -3.000 sujetos al fuero militar (Meléndez, 2010), que aunque no contaban con salarios muy altos, al menos si estables lo que les permitía sobrevivir de forma holgada (Márquez, 1999). Esa peculiaridad contribuyó a que la vida social se animara ya que parte de estas instalaciones militares así como las viviendas para sus moradores se localizaban a escasos metros del teatro López de Ayala y del paseo de San Francisco, lugares de esparcimiento por antonomasia. La disposición de los edificios públicos, así como los centros culturales marcaban esta ciudad amurallada que contaba con los baluartes construidos durante los siglos XVII y XVIII, recintos defensivos que lastraban su crecimiento pero que a su vez concentraron su vida social entorno del principal coliseo de la ciudad, el teatro López de Ayala, construido en 1886.

\subsection{Desarrollo urbanístico, económico y vida cultural}

Aunque el municipio iba remozando su estructura urbana, el casco antiguo mantenía intacta su fisonomía, motivado por la carencia de otros ingresos más allá de los labriegos locales, gran parte de ellos dependientes de los grandes terratenientes propietarios de las tierras fértiles o los comerciantes. El perímetro urbano de Badajoz apenas se había modificado durante los últimos siglos. Se circunscribía en esta época al recinto amurallado que a modo de cinturón ejercía de frontera y defensa, lo que impedía su crecimiento o expansión económica.

Si realizamos el perfil urbanístico, Badajoz presentaba un estado lamentable: calles sin empedrar, sin agua corriente hasta la llegada del gobierno de la República. Destacan la inexistencia de urinarios o recintos donde depositar la basura o la convivencia de vendedores ambulantes con los famosos y pintorescos aguadores que tantas fotografías para el recuerdo de la ciudad han protagonizado. La propagación de las enfermedades infecciosas formaba parte de la vida cotidiana. Por ello, no es de extrañar que los datos de población fueran tan cambiantes a la vista de las dificultades de un verdadero desarrollo demográfico. Pero todas estas dificultades no restaron a Badajoz de una vida cultural bastante agitada, aunque hay que considerar que el hecho de que se trate de un municipio con una climatología agradable, con algunas plazas ajardinadas y los propios baluartes conservados perfectamente en esta época, ayudaron a que se organizaran gran número de representaciones teatrales, óperas, zarzuelas, se asentarán circos y se organizaran conciertos al aire libre. Todo ello único a que en Badajoz capital se localizaban varios centros culturales de interés para las distintas clases sociales que convivían en la sociedad pacense como el Café Mercantil, la Sociedad Liceo de Artesanos (que ofrecía veladas musicales y era conocida como la casa del pueblo artesano), la Sociedad Espronceda (una humilde entidad a la que pertenecía la clase media), el Casino (lugar de reunión de la clase 
alta), el Ateneo, el Centro Obrero, el Pabellón Extremeño (que en ocasiones sirvió para la proyección de películas) la Plaza de Toros o los circos ambulantes que se instalaban durante temporadas en la Memoria de Menacho.

Y es así como el desarrollo y posterior asentamiento de las salas cinematográficas se disponen en torno a esos centros culturales, militares o los espacios abiertos, lugares fundamentales alrededor de los que giraba toda la vida comercial, social y de esparcimiento durante décadas en esta capital que además atraía al público portugués que acudía habitualmente a Badajoz para disfrutar de su animada vida cultural y comercial. Algo parecido a lo que ocurría en la cercana localidad de Mérida (Caballero, 1999), donde los primeros cines se situaron en torno a la plaza de España y sociedades culturales.

\subsection{Primeras proyecciones en el coliseo más importante de la ciudad: Teatro López de Ayala}

El teatro López de Ayala es el principal coliseo de la ciudad, construido en 1886. Un teatro a la italiana cuya fachada está situada en la plaza de Minayo y lindaba con el céntrico paseo de San Francisco. La sala se construye en el entorno histórico de renovación urbana que vivía el país a finales del siglo XIX que concluyó con la construcción de numerosos teatros alentados por "una creciente burguesía" (Cerro, 2002, p. 23). A pesar de las vicisitudes económicas y políticas que atravesó para ponerse en marcha, después de superar 25 años de una larga travesía burocrática, abrió sus puertas al público el 30 de octubre de 1886 en la plaza de Minayo, ubicada en el centro neurálgico de Badajoz. Aunque fue el Ayuntamiento quien sufragó los costes de la edificación, debido a las deudas que había contraído con varios empresarios de la ciudad, les cedió la propiedad para propiciar su apertura que hubiera sido imposible debido a la penuria que padecía el consistorio.

Solo habían pasado poco más de diez años de su inauguración cuando se convertirá en la sala pionera en realizar las primeras exhibiciones en 1897. Precisamente esa primera proyección de fotografía animada en Badajoz tiene lugar el día 17 de enero en 1897 (El Heraldo, 1897). Consistía en una hora de magia, con un número titulado El hombre impalpable ejecutado por el Sr. Robin y una exhibición cinematográfica compuesta por diez cuadros (Pulido, 1997). Después de estas exhibiciones se harán de forma esporádica, compartiendo programación con óperas, zarzuelas, teatro, conciertos, entre otros. Pero el cine no desaparecerá totalmente de su programación aunque habrá que esperar a mediados de la segunda década del siglo XX para comprobar que las proyecciones ya eran un atractivo permanente para los espectadores y una fuente de ingreso para los empresarios.

\subsection{Primeros locales de exhibición: barracas, pabellones y salas estables}

La ubicación del teatro López de Ayala, junto a los acuartelamientos militares, edificios administrativos así como las sociedades culturales no pasó desapercibido para los empresarios ambulantes del cine que instalaron sus destartaladas barracas en la plaza de Minayo, a escasos metros del principal teatro de la ciudad 
donde el empresario andaluz Antonio de la Rosa en 1898 ubicó una caseta de madera, espaciosa con asientos de madera y adornado con cretona con un rótulo en el que se leía Cinematográfo Lumiére (Alfaro, 1960). Después de estas primeras incursiones vendrían los pabellones cinematográficos, algo así como barracas de feria estables, de las que tomaban su forma, hechas de arquitectura legal y normalmente efímeras que eran construidas para durar meses, durante más tiempo que las denostadas barracas subordinadas a las ferias. Precisamente la situación de ambas instalaciones provisionales estarán ligadas estrechamente a los lugares de paso de los pacenses de ésta época. La conexión entre estos empresarios ambulantes y los propietarios que explotaban el cine en el teatro López de Ayala era inexistente, pero lo que parece claro es que los que pretendían tener éxito con el cine en épocas estivales o vinculadas a la feria lo hacían siempre pensando en instalarse próximos a los lugares de esparcimiento por antonomasia. De hecho, ambos negocios pujaban por atraer a un público que se mostraba dividido por el ocio, pero más bien era el precio de las entradas lo que marcaba estas diferencias. Las barracas y pabellones cobraban casi la mitad por una sesión cinematográfica que los empresarios del López de Ayala (González, 2016).

Todos estos lugares estaban concentrados en las zonas vitales de la ciudad. En torno a los centros culturales, militares y administrativos que fueron creciendo al mismo tiempo que se construían los edificios más representativos e históricos. De esta forma, el cine intensifica la vida cultural en los espacios urbanos históricos que se reconvierten en magníficos asentamientos para la proyección de imágenes en movimiento.

Otro de los puntos de interés para el cine fue el antiguo Fomento de las Artes y Unión Artística donde se instala un nuevo proyector de fotografía animado conocido como Vitágrafo Mágico (Pulido, 1997, p. 76). De esta forma, en poco tiempo Badajoz contaba con distintas salas y lugares para las proyecciones cinematográficas como puede apreciarse en la figura 1.

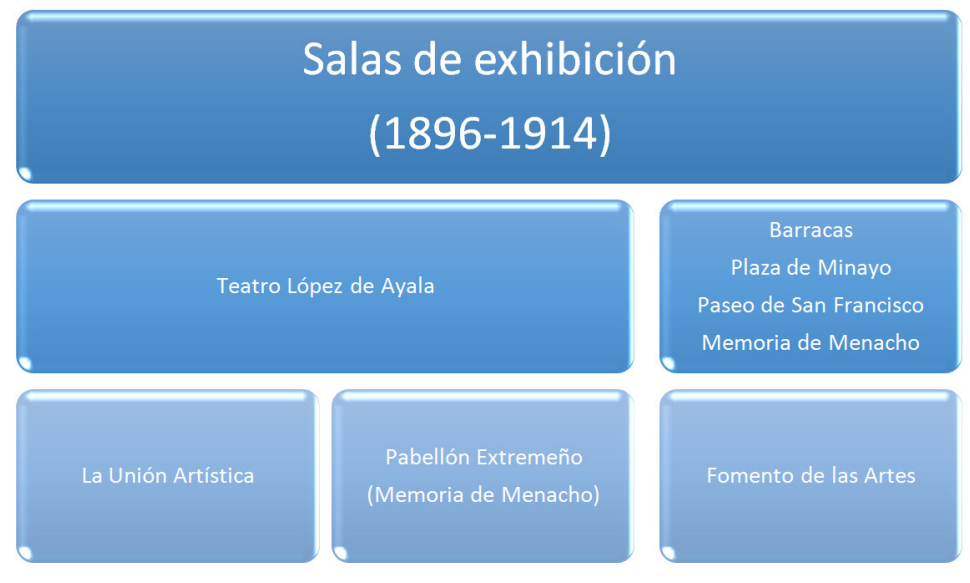

Figura 1. Salas de exhibición en Badajoz desde 1896 hasta 1914. Elaboración propia

La posterior expansión de las salas daría lugar a la ampliación del número de cines, a su estabilidad y aunque alguna de ellas se mantuvo de forma inalterable en los mismos lugares, surgieron nuevos lugares de exhibición de diferente naturaleza. Como puede apreciarse en la figura 2, se mantienes algunas y se 
incorporan dos nuevas salas, dedicadas exclusivamente a la proyección de películas.

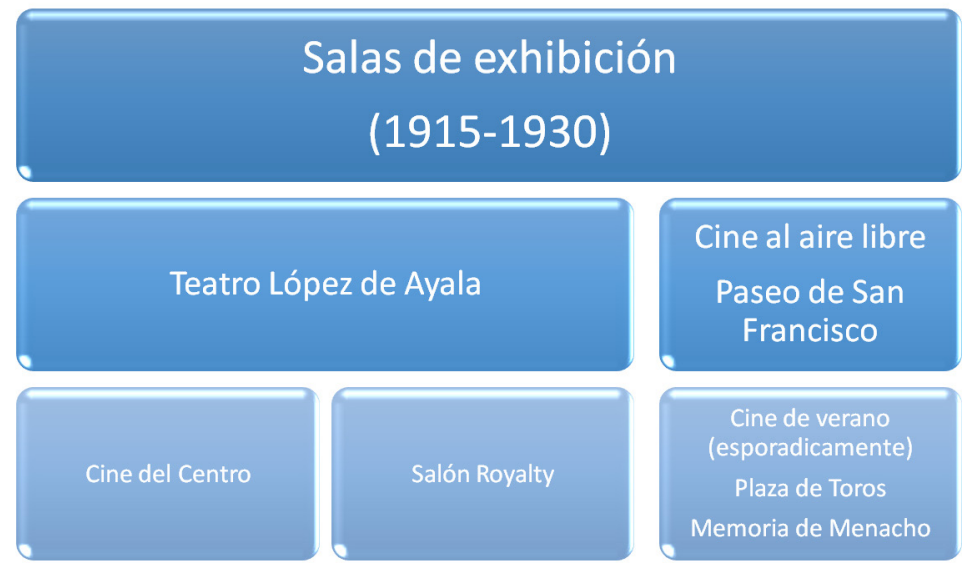

Figura 2. Salas de exhibición en Badajoz desde 1915 hasta 1930. Elaboración propia

\section{Ubicación de las salas y su conexión con el urbanismo}

Para realizar la parte de este estudio no ha sido necesario recurrir a planos antiguos de Badajoz ya que la cartografía de la ciudad se ha mantenido casi inalterable con el paso de los años. Cien años después, baluartes, plazas, paseos, calles y casi los mismos edificios que albergaron las exhibiciones en los primeros años de la llegada del cine se mantienen en los mismos lugares. Algunos de ellos, como el teatro López de Ayala, conservan su actividad cultural, aunque ahora alejada de las proyecciones.

Todo esto ocurría en un contexto de una leve recuperación económica, cuando se observan los cambios más notables y que se aprecia en una notable arquitectura local cuando se construyen en la década de los veinte gran parte de los edificios más singulares En torno a 1910-1930 se construyen los edificios más emblemáticos como los de uso comercial de La Giralda o Las Tres Campanas, la primera sala estable cinematográfica, Salón Royalty, la Casa Ramallo, la vivienda de los Albarrán, los Puebla, la casa Álvarez o la conocida como la casa de los Buiza, todos ellos pertenecientes a las familias Albarrán, Ramallo o Álvarez Buiza -entre otros- dedicados al pujante comercio de esta década de recuperación económica. La mayoría de estilo modernista, atribuidos a los mejores arquitectos de la época, algunos de gran prestigio nacional (González, 2011).

El emplazamiento estratégico de las salas de exhibición puede observarse en el plano cuyo cinturón de color amarillo -que se corresponde en la actualidad con grandes avenidas- nos sitúa en lo que eran las antiguas murallas, algunas de ellas desaparecidas, pero no su perímetro, enmarcado por los baluartes magníficamente conservados en pleno siglo XXI. 


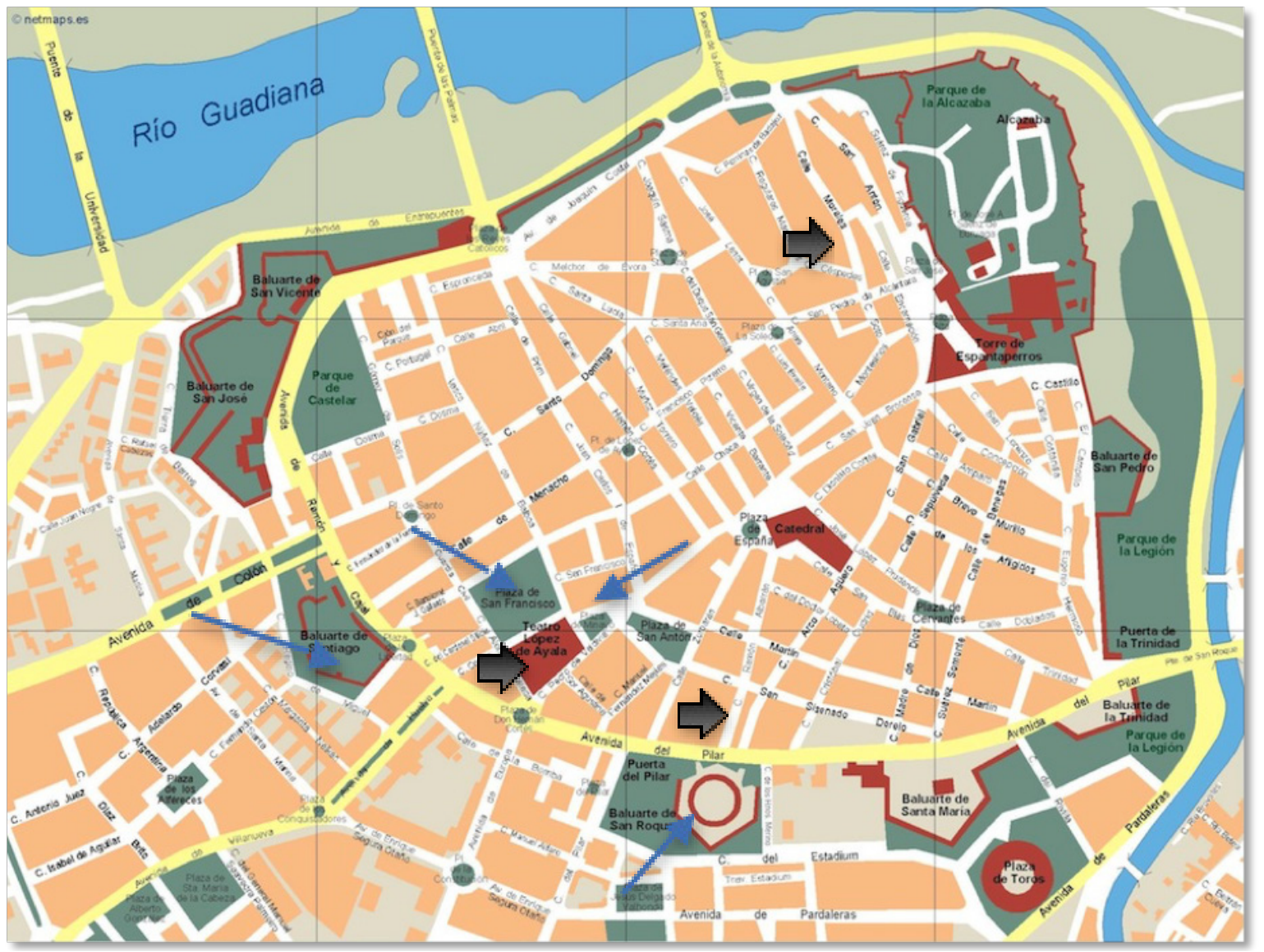

Figura 3. Plano de la ciudad de Badajoz actual y las zona donde se realizaron exhibiciones cinematográficas en las primeras décadas del s. XX. Fuente: http://www.netmaps.net/netmaps/mapa-badajoz/

Es cierto que puede interpretarse que estas ubicaciones obedecían más a cuestiones estratégicas más que a facilitar los accesos de los espectadores. Para llegar a cualquiera de las salas que se reseñan en este estudio solo había que desplazarse unos cientos de metros. Señalado esto, solo queda situarlos en el plano y establecer una cierta conexión entre ellos que parece obedecer más a cuestiones de interés por atraer a un público que ya transitaba por esas zonas y que consumía este tipo de espectáculos con total facilidad.

En el mapa pueden observarse las ubicaciones con flechas que señalan las distintas salas que existieron esos años. En azul aparecen los lugares donde se realizaron proyecciones al aire libre y serían las siguientes:

- Baluarte de Santiago. Conocido como Memoria de Menacho porque allí se erigió un monumento al general Menacho después de la Guerra de la Independencia. En este recinto se instalaban los circos que acudian a la ciudad con motivo de las ferias, las primeras barracas de principios de siglo, pero la presencia más importante se localiza entre los años 1910 a 1922 cuando el conocido como Pabellón Extremeño se instalaba en esta explanada durante más tiempo del que permanecían las barracas.

- Plaza de Toros. Ubicada dentro del recinto amurallado en el conocido como baluarte de San Roque. Las proyecciones fueron regulares durante algunos años. 
- Paseo de San Francisco. Punto neurálgico de la ciudad utilizado de forma continua durante los veranos desde 1903 para la exhibición cinematográfica. Su ubicación y la extensión del mismo se convirtieron en el lugar idóneo para atraer a los espectadores de la época. Como puede observarse en la figura 4, estaba rodeado de edificios públicos y junto al teatro López de Ayala. Contaba con una explanada lo suficientemente amplia como intalar más de 300 sillas y un telón que hacía las veces de pantalla.

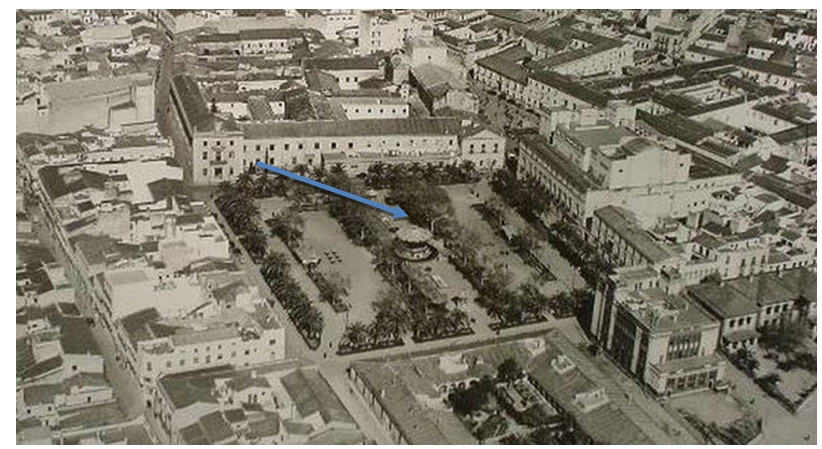

Figura 4. Vista aérea Paseo de San Francisco 1940. Colección privada

Por otro lado, en la figura 3 aparecen señaladas con una flecha gris los locales cerrados que se ubicaron todos ellos en el interior del recinto amurallado. Algunos son edificios que se reutilizaron para la exhibición después de haber sido empleados para usos sociales. Alguno de ellos son los siguientes:

- Cine del Centro. Situado en la calle Ramón Albarrán, cercana a la catedral y al Ayuntamiento de la ciudad. Ocupó el antiguo Centro Obrero y funcionó como cine entre 1927 hasta 1929. Se situaba a tan solo 200 metros de la antigua plaza de Toros y a poco más de 500 metros del teatro López de Ayala. Como puede observarse en la figura 5, el edificio que ocupaba y que mantiene un uso cultural está en pleno Casco Histórico y del que se conservan vestigios de la época como la pantalla y un antiguo proyector. Al fondo de la imagen se vislumbra el actual Palacio de Congresos, otro de los lugares que ha modificado su fisonomía pero que mantiene su utilidad cultural. 


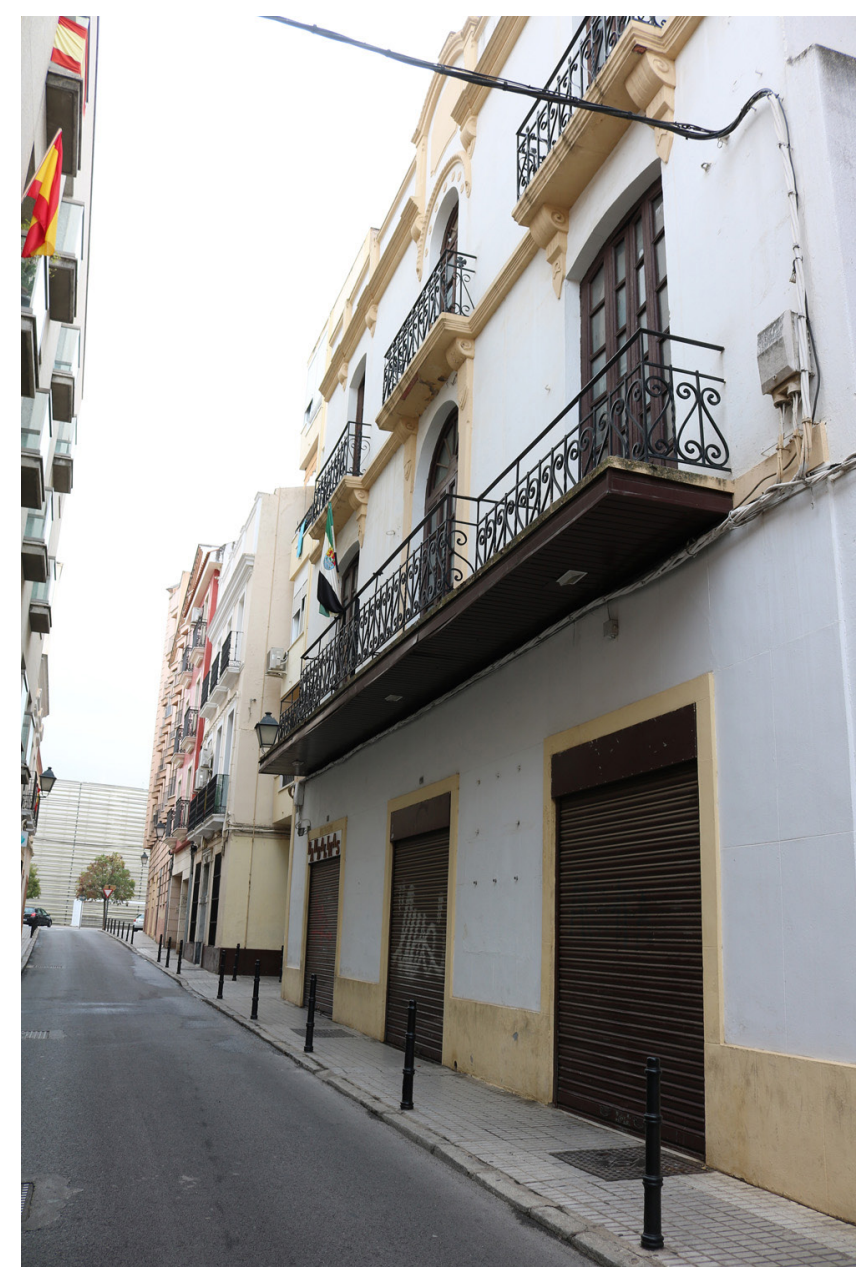

Figura 5. Fachada del antiguo Cine del Centro, al fondo el solar que ocupaba la Plaza de Toros, actualmente Palacio de Congresos. Elaboración propia

- Salón Royalty. La sala de exhibición más alejada del centro comercial y cultural de la ciudad estaba ubicado en la calle Chapín donde anteriormente funcionó el Salón Cinema durante dos años y también otro anteriormente conocido como Salón Chapí. Fue el primer local que dedicó toda su programación a las exhibiciones desde su apertura en 1923 hasta su cierre temporal en 1929. Debido a que no se encontraba situado en las zonas de mayor tránsito de la ciudad, el empresario que lo pone en marcha la primera vez solicita al Ayuntamiento permiso para mejorar el pavimento. Como puede oberservarse en la figura 6, se trataba de una calle del Casco Antiguo, intramuros, cercana a otros puntos de interés comercial de Badajoz como era la plaza de la Soledad donde se encontraban los dos grandes almacenes más conocidos: La Giralda y Las Tres Campanas. 


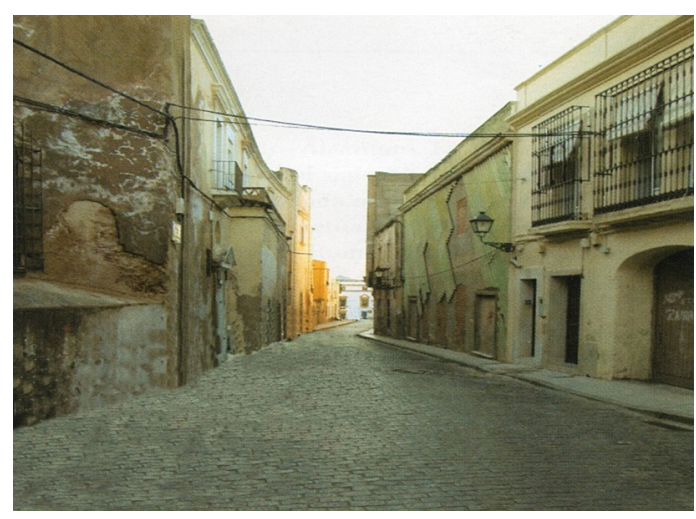

Figura 6. Fachada del Salón Royalty en torno a 1990. Láminas colección diario HOY

Además de las salas reseñadas, tan solo algunas veladas cinematográficas localizadas en lo que posteriormente se conocería como el barrio de la Estación, situado junto a la estación del ferrocarril, alejado de los puntos de interés de la ciudad.

\section{Rodajes de la ciudad}

En las investigaciones que se han realizado sobre el entorno de las historias locales del cine uno de los aspectos que se han abordado han sido los rodajes de asuntos locales. Este aspecto es traído aquí para analizar cómo el cine también sirvió para mostrar a los espectadores cómo era su ciudad. Desde las primeras incursiones de los fotógrafos locales, el caso de la familia Garrorena fue el más paradigmático en la capital pacense, hasta los realizados por los empresarios del teatro López de Ayala, Manuel Muñoz Márquez y Miguel Silgo Morán en los años veinte, ambos, o bien por afición o por encargo, rodarán imágenes en las que distintos espacios y paisajes de la ciudad son los protagonistas. La reacción del público siempre era de satisfacción, no en vano era la primera vez que gracias a estas rudimentarias películas se asomaban a su ciudad.

Desde que los hermanos Lumière hicieron irrumpir una locomotora en un café de París (1889), la única manera de conocer ciudades no es caminando por ellas. El mundo se asomó a Berlín por el ojo mecánico de Ruttman o a Niza por el de Vigo, pero además del registro documental, el cine optó también por una narrativa, que a través de ficciones, representó la realidad. La construcción espacial que el cine hace de la urbe se traduce en la imagen que llega al espectador, su interpretación hace parte de una memoria que muchas veces es más poderosa que la realidad misma' (Llorca, 2012, p. 371).

Fernando Garrorena realiza el rodaje de imágenes de Carnaval infantil, vistas de Badajoz y El minué (Pulido, 1997, p. 67-69) y un ejemplo similar encontramos en Cáceres. Sería Julio Borreguero quien exhiba en 1904 en el Cinematógrafo Franco-Español, Panorámicas de Cáceres. En ambos casos observamos cómo la atracción por la ciudad enmarca ya el interés de esos pioneros. A estos rodajes le seguirían algunos más en la segunda década del siglo XX. Las siguientes noticias que se encuentran sobre cintas rodadas en la ciudad no llegarán hasta 1912, cuando el 24 de junio se anuncia la exhibición de varias películas. Feria y Fiestas de 
Badajoz, Llegada de un tren procedente de Portugal a la ciudad a la feria de mayo de Badajoz, Vistas de la ciudad de Badajoz y Lidia de tres toros.

Los más prolíficos serán los empresarios Manuel Muñoz y su socio Miguel Silgo. Durante estas primeras décadas además de dedicarse al negocio cinematográfico, siempre estarán dispuestos a impresionar todos los acontecimientos locales. Ambos realizarán en poco más de 15 años más de veinte películas tanto de interés local como familiar, de las que se han conservado algunos fotogramas. Desde mostrar la visita en 1914 de las autoridades locales a la Granja Escuela a rodar imágenes poco después de que el aviador pacense Montero se estrellara con su avioneta en un lugar próximo a Badajoz y que provocó un gran revuelo en el teatro López de Ayala tras su proyección. Es así como los pacense pudieron solazarse con las imágenes que esas filmaciones le proporcionaban.

\section{Conclusiones}

Investigar sobre la relación entre cinematografía y la vida de una ciudad es adentrarse de forma paralela en su historia y permite extraer interesantes conclusiones sobre la influencia de la conformación de las urbes y su desarrollo cultural, concretamente en la expansión del cinematógrafo, una disciplina que se expandió y compartió espacios con escenarios antaño utilizados para otras artes escénicas como el teatro, la ópera o las zarzuelas.

Profundizar en ello implica también hallar historias trufadas de anécdotas y detalles que nos ayudan a entender mejor la ciudad, su evolución y su desarrollo posterior. Es imposible no historiar los acontecimientos sin mirar de cerca cómo influyó de manera notable la ubicación de los centros culturales y neurálgicos de la ciudad: cuarteles militares, instituciones políticas, sociales y culturales. $Y$ es así como hilando esta pequeña historia local se consigue acercarse a datos que nos subrayan la importante relación entre la vida ciudadana en la consolidación del fenómeno cinematográfico. Datos que nos ayudan a entender y comprender mejor nuestra historia y esa relación continúa entre el ocio y el entretenimiento con las instituciones políticas, educativas, militares y comerciales. Por otro lado, la importancia para la época que tenía mostrar a través de primitivos rodajes las imágenes en movimiento de cómo era la ciudad fuera y dentro de sus murallas.

Se abre de este modo la puerta a otros estudios más profundos que analicen la relación entre los edificios que albergaron las exhibiciones cinematográficas en este primer periodo y el uso cultural que de ellos se hacen en la actualidad.

\section{Referencias}

- $\quad$ Alfaro, M. (1960). Más estampas de Badajoz. Badajoz: Publicaciones del Excelentísimo Ayuntamiento de Badajoz.

- $\quad$ Barrientos, M. (2017). Cinematógrafo y ciudad. Integración del nuevo espectáculo en el espacio urbano de la Sevilla de finales del XIX y principios del XX. El factor tranvía. En F. Garcia (director), Congreso Internacional Cidades Criativas. Simposio llevado a cabo en el V Congreso Internacional Cidades Criativas 2017, Centro de Investigaçao Transdisciplinar, Cultura, Espaço E Memoria- Icono 14. Porto. Recuperado de https://goo.gl/kGsDBj 
- $\quad$ Bohoyo, I. (1984). Situación socio-económica y condiciones de vida en la provincia de Badajoz (1880-1902). Badajoz: Biblioteca Popular Extremeña, Universitas Editorial.

- $\quad$ Boletín de Estadísticas Municipales de Badajoz. Ayuntamiento de Badajoz.

- $\quad$ Caballero, J. (1999) Historia Gráfica del cine en Mérida, (1898-1998). Mérida: Editora Regional de Extremadura. - $\quad$ Cardoso, J.M. (2015) La transición del cine mudo al sonoro en Badajoz, (1929-1933). (Tesis doctoral). Universidad Complutense, Madrid. Recuperado de http://eprints.ucm.es/42227/

- $\quad$ Cerro, J. (2002). Una arquitectura para el espectáculo, herencia y cambios en el Palacio Teatral en el cine (19001939): Anales de la literatura española contemporánea, ALEC. Col. 27, № 1, págs. 23-44.

- González, A. (2016). La Exhibición Cinematográfica en Badajoz 1914.1918. (Tesis Doctoral). Universidad Complutense, Madrid. Recuperado de http://eprints.ucm.es/38073/

- $\quad$ González, J.M. (2011). Guía de arquitectura de Badajoz (1900-1975). Mérida: Junta de Extremadura y FEDER (Fondo Europeo de Desarrollo Regional).

- $\quad$ Lozano, M. M. (1998). Urbanismo y arquitectura de Extremadura en torno a 1898, una etapa de tránsito. Revista de Estudios Extremeños. Vol. 54, Nº3, pp. 973-1016. Recuperado de https://goo.gl/cU59Zz

- Llorca, J. (2012). Cine, ciudad y arquitectura, apuntes metodológicos. El caso de El grupo de Cali. Revista CS, en Ciencias Sociales, N 9. Doi: http://dx.doi.org/10.18046/recs.i9.1226

- Márquez, J. (1999). Aquellas tardes de agosto. Badajoz: Colección narrativa, Diputación de Badajoz.

- Meléndez, A. (2010). Apuntes para la historia militar de Extremadura. Badajoz: 4 Gatos.

- $\quad$ Pulido, C. (1997). Inicios del cine en Badajoz (1896-1900). Mérida: Editora Regional de Extremadura.

- $\quad$ Rodríguez, V. (2017). Imágenes de la ciudad. El Zócalo de la ciudad de México, escenario de eventos artísticos y culturales. En F. Garcia (director), Congreso Internacional Cidades Criativas. Simposio llevado a cabo en el $V$ Congreso Internacional Cidades Criativas 2017, Centro de Investigaçao Transdisciplinar, Cultura, Espaço E Memoria- Icono 14. Porto. Recuperado de https://goo.gl/kGsDBj 